\title{
Oral Complication of Radiation Therapy
}

National Cancer Institute

\section{Source}

National Cancer Institute. Oral Complication of Radiation Therapy. NCI Thesaurus. Code C115322.

Any oral disorder occurring as a consequence of radiation therapy. 